\title{
A PARTICIPAČ̃o DAS MULHERES COM CÂNCER DE MAMA NA ESCOLHA DO TRATAMENTO: UM DIREITO A SER CONQUISTADO
}

Sandra Lucia Arantes ${ }^{1}$ Marli Villela Mamede

Arantes SL, Mamede MV. A participação das mulheres com câncer de mama na escolha do tratamento: um direito a ser conquistado. Rev Latino-am Enfermagem 2003 janeiro-fevereiro; 11(1):49-58.

Esta pesquisa pretendeu identificar como as mulheres com câncer de mama se percebem enquanto sujeitos no processo de tomada de decisão sobre seu tratamento. Os objetivos foram: identificar determinantes sociais e políticos presentes no processo de socialização dessas mulheres que contribuíram para a adoção de um estilo de participar, e compreender o significado da participação tal como foi percebido por elas no momento de decidirem sobre seu tratamento. A fundamentação teórico-metodológica foi inspirada no Interacionismo Simbólico. A amostra constou de nove mulheres com câncer de mama. A entrevista semi-estruturada conduziu à coleta de dados, assim como as anotações de campo e os dados do prontuário. Tomando-se a dialética hermenêutica como caminho do pensamento interpretativo dos dados, foi possível apreender duas grandes unidades temáticas: 'construção da identidade feminina' e 'estilo de participação na escolha do tratamento', as quais nos permitiram apreender o que, para elas, significou falar de limites e, portanto, de ética. Elas interpretaram que não participaram do processo de tomada de decisão por serem consideradas desqualificadas para decidirem sobre seus corpos e suas vidas portanto, como sujeitos de obediência à decisão médica, que se fundamenta no princípio da beneficência, sendo que atendimento à saúde se estrutura por meio de relações sociais hierarquizadas cujas relações de poder se dão entre classes, gêneros e saberes.

DESCRITORES: saúde da mulher, neoplasias mamárias, ética

\section{THE PARTICIPATION OF WOMEN WITH BREAST CANCER IN CHOOSING THEIR OWN TREATMENT: A STILL UNACHIEVED RIGHT}

The purpose of this study was to identify how women with breast cancer perceive themselves as subjects in the process of making decisions on their own treatment. Two objectives were pursued: (a) to identify social and political determinants that, by affecting the socialization process of these women, might have influenced them in adopting a style of participation, and (b) to understand the meaning of such participation, as it was perceived by these women at the time they decided on their treatment options. The theoretical-methodological support adopted was that of Symbolic Interactionism. The population sample included nine women with breast cancer. Semi-structured interviews allowed data to be gathered, and led to collecting further field notes and data from medical records. The hermeneutic dialectic method was employed as a compass for data interpretation, which made it possible to identify two broad theme units: 'construction of the female identity' and 'style of participation when choosing one's own treatment'. By means of these units it was possible to grasp what it meant for these women to deal with the issue of limits and, therefore, of ethics. In their view, they did not participate in the decision-making process, being regarded as unqualified to decide on the fate of their own bodies and lives. They were thus seen as obedient subjects in relation to medical decisions that are based on the principle of beneficence, where health care delivery is dependent on hierarchical social relationships and power structures are present between classes, genders, and levels of knowledge.

DESCRIPTORS: women's health, breast neoplasms, ethics

\section{LA PARTICIPACIÓN DE LAS MUJERES CON CÁNCER DE MAMA EN EL MOMENTO DE ESCOGER EL TRATAMIENTO: UN DERECHO A SER CONQUISTADO}

Esta investigación pretendió identificar como las mujeres con cáncer de mama se perciben en cuanto sujetos en el proceso de tomar decisiones sobre su tratamiento. Los objetivos fueron: identificar determinantes sociales, económicos y políticos presentes en el proceso de socialización de estas mujeres que contribuyeron para la adopción de un estilo de participar y comprender el significado de la participación, tal como fue percibido por ellas en el momento, de decidir sobre su tratamiento. La fundamentación teórica metodológica fue inspirada en el Interaccionalismo Simbólico. La muestra constó de nueve mujeres con cáncer de mama. La entrevista semi-estructurada condujo la recolección de datos, así como, las anotaciones de campo y datos de la historia clínica. Tomándose la dialéctica hermenéutica como el camino del pensamiento interpretativo de los datos, fue posible identificar dos grandes unidades temáticas: 'construcción de la identidad' y 'estilo de participación en el momento de escoger el tratamiento', las cuales permitieron aprender que significó para ellas hablar de limitaciones y por tanto, de ética. Ellas interpretaron que no participaron del proceso de tomar decisiones por ser consideradas descalificadas para decidir sobre sus cuerpos y sus vidas, por tanto, un sujeto de obediencia a la decisión medica, que se fundamenta en el principio de la beneficencia, donde la atención a la salud se estructura a través de las relaciones sociales jerarquizadas, cuyas relaciones de poder se dan entre clases, géneros y saberes.

DESCRIPTORES: salud de las mujeres, neoplasias de la mama, ética

\footnotetext{
${ }^{1}$ Mestre em Enfermagem Obstétrica, Professor Assistente do Departamento de Enfermagem da Universidade Federal de Mato Grosso do Sul, Doutoranda do Programa de Pós Graduação Enfermagem em Saúde Pública, e-mail: sarantes@nin.ufms.br; ${ }^{2}$ Professor Titular. Escola de Enfermagem de Ribeirão Preto da Universidade de São Paulo, Centro Colaborador da OMS para o desenvolvimento da pesquisa em enfermagem
} 
INTRODUÇÃO

$E_{\text {studos têm comprovado que as pacientes com }}$ câncer de mama que tiveram oportunidade de participar na tomada de decisão de seu tratamento vieram a experimentar menos ansiedade e depressão, como também as mulheres mais jovens ou com nível educacional mais elevado foram aquelas que dispuseram de maior controle na tomada de decisão $0^{(1-4)}$.

O esclarecimento sobre a natureza e os objetivos dos procedimentos diagnósticos, preventivos ou terapêuticos, é um direito do paciente, bem como de ser informado sobre sua invasibilidade, duração do tratamento, seus benefícios e prováveis desconfortos, e dos possíveis riscos físicos, psicológicos, econômicos e sociais por que possa vir a passar.

Alguns autores explicam que a falta de informações apropriadas sobre o câncer e seus tratamentos pode ser uma das razões pelas quais as mulheres se sentem desconfortáveis quando são estimuladas a participar no processo de tomada de decisão $0^{(2)}$. A falta de informação ou a informação insuficiente, constituem os motivos mais fortes na justificativa das mulheres quanto a sua falta de condições para participar na tomada de decisão ${ }^{(3)}$.

No entanto, a não participação na tomada de decisão sobre os tratamentos a que serão submetidas, parece não se tratar apenas de desconhecimento das mulheres a respeito do câncer e das diferentes modalidades de tratamento, nem da falta de informações apropriadas e suficientes. Isso porque, por meio de discussões em grupos de reflexão de mulheres, fica evidente que elas não só desconhecem seus corpos, mas reconhecem o sistema médico como detentor de um saber que se legitima por intermédio de um poder sobre os $\operatorname{corpos}^{(5)}$. Identificam, ainda, que os profissionais médicos reproduzem o modelo hierarquizado e unilateral de comunicação. Isso talvez se deva ao fato de que, ainda hoje, estes detêm a maior parcela do poder instituído nos serviços de saúde, sendo, portanto, menos propensos a aderir a propostas inovadoras que buscam um certo nivelamento do conhecimento, pelo menos temporariamente, entre os participantes.

O exercício da cidadania é uma questão que vem recebendo cada vez mais atenção e reflexão dos profissionais de saúde que se dedicam aos portadores de câncer. É incontestável, hoje, que os direitos do cidadão devem ser respeitados em todas as etapas do processo saúde-doença.

O paciente tem o direito de ser ouvido, opinar sobre suas conveniências, dispor como proprietário exclusivo de seu corpo, partes e funções, e de decidir sobre sua própria vida. No sistema atual de assistência à saúde, tornam-se evidentes as muitas práticas que desconsideram o paciente como sujeito e pessoa em seu tratamento. E, com freqüência, é constatado, na ocasião do diagnóstico e definição do tratamento de mulheres com câncer de mama, que elas raramente participam desse processo. A questão da participação da paciente no seu processo de tratamento, inclusive na decisão sobre modalidades a que serão submetidas, deve ser conduzida dentro de uma proposta de um modelo assistencial traçado pela ética do cuidar de cidadãos, de forma a permitir que a mulher com câncer de mama torne-se sujeito de participação de sua própria assistência.

Nessa perspectiva, o atendimento ao princípio de autonomia no âmbito da assistência à saúde pressupõe que $o$ indivíduo, sadio ou doente, não se entregue cegamente aos profissionais de saúde. Nesse sentido, nesta investigação, procuramos identificar como as mulheres com câncer de mama se percebem como sujeitos no processo de tomada de decisão sobre seu tratamento. Para tanto, procuramos: identificar determinantes sociais, econômicos e políticos presentes no processo de socialização dessas mulheres, os quais tenham contribuído para a adoção de um estilo de participação em seu tratamento; e compreender o significado da participação, tal como percebido por essas mulheres, no momento de decidirem sobre o tratamento do câncer de mama.

\section{FUNDAMENTAÇÃO} METODOLÓGICA DE REFERÊNCIA

A fundamentação teórico metodológica adotada foi o interacionismo simbólico, isso porque, nessa perspectiva, o comportamento humano é entendido como um ato social e não meramente uma resposta do indivíduo a si mesmo e a outras pessoas que lhe respondem. A concepção interacionista concebe a vida social como um consenso estabelecido sobre as inter-relações, e, por isso, o sentido atribuído pelo sujeito às ações acaba sendo manipulado, redefinido e modificado por meio de um 
processo interpretativo consensual do grupo. O significado das coisas resulta da interação social que os seres humanos têm uns com os outros ${ }^{(6-7)}$.

Dando-se oportunidade às mulheres com câncer de mama de expressarem o sentido que dão a sua participação na escolha do tratamento, e de expressarem a imagem que têm sobre o exercício da cidadania, tornase possível facilitar sua reflexão sobre sua participação nesse processo e, conseqüentemente, sobre seus direitos à saúde.

Desse modo, é possível considerar que as ações das mulheres com câncer de mama e, no caso em estudo, sua participação na escolha de seu tratamento, são ações revestidas de significados. Acreditamos que o significado que essa experiência terá para elas influenciará seu comportamento e conduta quanto à forma de participação.

O depoimento pessoal de mulheres com câncer sobre suas experiências de vida colhidos através de entrevistas semi-estruturadas foi o método de coleta de dados nesta pesquisa.

Para a captação da realidade empírica, foram realizadas entrevistas com nove mulheres portadoras de câncer de mama residentes em Campo Grande, Mato Grosso do Sul e municípios vizinhos, no período em que estavam sendo submetidas aos procedimentos diagnósticos ou imediatamente à definição do diagnóstico médico, quando a terapêutica é instituída.

Antes do início da entrevista, foi explicitada a finalidade da pesquisa, assegurado o anonimato na apresentação dos dados e obtida a autorização para uso do gravador. Foi, ainda, esclarecido às participantes que a participação era livre, conforme preconiza a Resolução 196/96, apresentando o Termo de Consentimento Livre e Esclarecido, o qual foi feito em duas vias, permanecendo uma cópia com a participante.

O diário de campo foi utilizado para o registro das observações livres.

Para completar e confirmar as informações clínicas e os dados colhidos, foram utilizados documentos oficiais, que, neste estudo, foram os dados do prontuário da paciente, tais como laudos de exames citopatológicos e imuno-histoquímicos e descrições clínico-cirúrgicas da ficha clínica.

Situando o objeto deste estudo no significado da ação, buscamos identificar, por meio do método hermenêutico-dialético, a ilusão ideológica de liberação da mulher em relação aos padrões de pensamento que pudessem estar nela profundamente gravados, limitandoIhe a autocompreensão. De fato, este é o modo pelo qual o pensamento produz racionalidade, pois é capaz de dar conta de uma interpretação da realidade, colocando a fala em seu contexto, para entendê-la a partir de seu interior e no campo da especificidade histórica e totalizante em que é produzida. Tanto a hermenêutica como a dialética têm o ser humano como ponto de partida, a práxis social como objeto de análise e a afirmação ético-política do pensamento como sentido da busca ${ }^{(7)}$.

A hermenêutica é a busca de compreensão do sentido que se dá à linguagem, por ela constituir o núcleo central da comunicação entre os seres humanos em seu dia-a-dia. O homem se complementa na comunicação. Ela é condicionada pelo contexto do analista e pressupõe compreensão compartilhada. A hermenêutica traz para o primeiro plano as condições cotidianas da vida e promove o esclarecimento sobre as estruturas profundas. Traz, também, a intersubjetividade de uma intenção, o núcleo da ação ${ }^{(7)}$.

A tarefa da hermenêutica é trazer do passado o que é essencial para nosso presente pessoal, para a autocompreensão, ou, mais exatamente, para a experiência que temos do ser. Compreender algo é compará-lo ao já conhecido. Optamos pela interpretação temática na análise dos dados, a qual, por meio de símbolos, metáforas, exprime o que a palavra é incapaz de significar.

\section{ANÁLISE E INTERPRETAÇÃO DOS DADOS}

As idades das participantes variaram de 34 a 74 anos, sendo que seis delas tinham de 34 a 45 anos, e duas vivenciavam a década de 70 anos. $O$ baixo grau de instrução encontrado no grupo de entrevistadas, de 3,4 anos, retrata um dos problemas sociais mais graves do Brasil. Acerca do estado civil, houve predominância de mulheres casadas, no universo pesquisado, bem como de mulheres que exercem ou exerceram atividades fora do lar.

A mastectomia unilateral foi o tratamento indicado para a maioria das mulheres do grupo. Apenas em um caso foi indicada a mastectomia bilateral. Em quatro casos, a mastectomia total estava sendo indicada, enquanto a mastectomia parcial estava sendo recomendada para três outras, com a possibilidade de, 
antes ou após a cirurgia, ser necessária uma complementação com terapias adjuvantes local e sistêmica. Em apenas um caso foi decidido o uso exclusivo de radioterapia.

Durante o procedimento analítico, configuraramse as seguintes unidades de análise: 'construção da identidade feminina' e 'estilo de participação na escolha do tratamento'.

\section{CONSTRUÇÃO DA IDENTIDADE FEMININA}

Para o grupo das mulheres estudadas, falar sobre a construção de sua identidade feminina significou reviver fatos e acontecimentos de sua 'infância e adolescência'. Destacaram aspectos que caracterizaram 0 desenvolvimento de sua 'sexualidade', situando as mamas em seu espaço de vida e revelando que o 'cuidado com o corpo' relaciona-se com a reprodução.

Ao narrarem o vivido na infância e adolescência, deixaram transparecer que esses estágios de desenvolvimento foram permeados por sentimentos de abandono, medo e falta de solidariedade, mas, ao mesmo tempo, por alegrias, o que se evidenciou ao se recordarem das brincadeiras infantis.

O sentimento de abandono, traduzido por perda da família biológica ou da mãe, foi configurado pelas mulheres que o experimentaram como algo maléfico a suas vidas e, em algumas situações, como desumano. $O$ seguinte depoimento retrata tais conteúdos: Olha..., eu fui criada por pessoas estranhas, eu não fui criada por minha mãe nem meu pai..., eles me deram quando eu tinha 3 meses de nascida. Eu não sei nada sobre a minha família, quando eu fui ver minha mãe verdadeira, eu tinha 9 anos, e ela nunca mais procurou saber se eu estava viva ou morta, eu cresci, fiquei moça, ela nunca procurou saber. (E1)

Ao identificarem a perda como um fenômeno da vida humana, as mulheres situam-na como carregada de conflitos morais não resolvidos: ...eles me deram porque minha mãe tinha medo de eu morrer. (E1)

$\mathrm{Na}$ adolescência, o medo do abandono foi narrado como alguma coisa altamente negativa, à qual estariam sujeitas, caso se permitissem uma abertura às descobertas das novas sensações e sentimentos despertados nessa fase da vida. As entrevistadas assim se revelaram: Tinha um medo danado de eu me entregar para alguém e esse alguém me abandonar e eu ficar ao deus-dará. (E1)
Para essas mulheres, a instituição familiar incumbiu-se de mostrar-lhes os campos de domínio feminino e masculino, a imposição de uma estrutura de poder entre os gêneros, com exigências para que meninos e meninas se enquadrem nos moldes de uma sociedade patriarcal, em que as posições e papéis são assumidos de forma diferenciada, de acordo com cada gênero: ...falava que não era hora de ficar conversando no portão, já era hora de moça estar na cama, não era hora de ficar no portão, eu ficava brava porque eu não estava fazendo nada. (E1)

Foi apreendido por essas mulheres que o processo de constituição e instituição dos papéis sexuais é cruel às meninas, como expresso na seguinte fala: Na minha época de criança, tinha que ficar cuidando dos irmãos e dos primos. (E7)

Isso se perpetua na vida adulta da mulher, como relatado neste depoimento: Estou longe da minha família, os homens sozinhos se virando, fazendo minhas coisas, ...(E3)

No grupo estudado, houve reconhecimento da falta de solidariedade dentro do próprio gênero nas primeiras fases de vida (infância e adolescência), quando a mãe se conforma ao modelo hierarquizado de poder e, usando o direito de mando e de opressão, promove um distanciamento na relação mãe-filha: $A$ mãe nunca teve liberdade de conversar comigo. Nunca falou das coisas dela. (E4); Ela não era minha amiga. Era mãe e muito brava. (E6)

Esta forma de ser e relacionar-se, para as mulheres do grupo estudado, repercutiu na forma de serem na vida adulta e de relacionarem-se consigo mesmas e com os outros: Tenho dificuldade para falar os meus pensamentos, vergonha de falar. Durante toda a vida eu não gostei de falar. Não tenho coragem nem de conversar com o médico. (E4)

$\mathrm{Na}$ visão das mulheres, o modelo hierarquizado paternalista se reproduz, pois elas identificaram um caráter assimétrico nas relações sociais entre mãe e filha, caracterizado pela força de uma e fragilidade da outra.

Essa posição desigual e assimétrica na estrutura de poder também é revelada com relação aos profissionais de saúde e aos serviços de saúde. Nessa relação desproporcionada, o cuidado prestado pelos profissionais de saúde anula a pessoa que é objeto desse cuidado, dando-se uma passagem desapercebida do saber ao poder, de conseqüências lamentáveis, pois a pessoa chega a ser apagada como individualidade singular ${ }^{(8)}$.

No mundo do trabalho, a aquisição de responsabilidades extras ao ambiente doméstico, como cuidar dos pais, irmãos ou primos, ocorreu de forma 
prematura para as mulheres estudadas, o que, em sua visão, tolheu suas possibilidades de auto-realização e ascensão sociocultural: Morei em sítio, sempre trabalhando na roça. Nunca gostei de brincar. Trabalhava na colheita de café. Estudei só quando fui morar na cidade. Trabalhava em casa de dia e ia à noite para a escola.(E5)

O lúdico, tão característico da infância, nas brincadeiras infantis, é lembrado com muita satisfação pelas mulheres estudadas. No entanto, elas reconhecem que, por pertencerem ao grupo do sexo feminino, a liberdade e a autonomia para a satisfação de seus desejos foram refreados: A gente tinha que ter modos para sentar, a gente tinha que saber o que ia conversar, né?

Tais comentários fazem sentido, pois não há autonomia se não houver liberdade de pensamento, nem há opções quando se dispõe de apenas uma possibilidade de escolha. Do mesmo modo, quando inexiste liberdade de ação, de acordo com a opção desejada, a ação empreendida não poderá ser considerada autônoma ${ }^{(9)}$.

A construção da identidade feminina, na esfera da sexualidade, revela que, para o grupo de mulheres estudadas, o processo de socialização incumbiu-se de mostrar que a virgindade ocupa uma posição de destaque na entrada para o mundo das casadas, que o desejo sexual não é central à expressão sexual feminina, que o exercício da sexualidade é uma forma de concretizar os papéis sociais determinados às mulheres. Incumbiu-se, ainda, de mostrar que as mudanças corporais, com a chegada da menstruação e o crescimento e desenvolvimento das mamas, apelam para a dimensão simbólica do corpo humano, o que tem ligações com a tradição cultural da pessoa, seus temores, esperanças e crenças.

A virgindade, para muitas, foi marcada como uma condição para o matrimônio, cujo pré-requisito nem sempre se associava a seu desejo: Perdi a virgindade após o casamento. (E1). É interessante notar que as mulheres, embora soubessem que a perda da virgindade ocupasse um espaço e tempo definidos na vida feminina de sua época, era algo a ser vivenciado com o outro gênero, exclusivamente por meio de uma instituição: o casamento: Eu nunca casei, sempre tive medo de namorar, eu sou pura até hoje. Não me arrependo. (E4)

A transgressão dessa regra, para algumas, significou superar uma imposição que as fazia objetos e não sujeitos de suas vontades e desejos: Eu me perdi com 14 anos com o meu namorado. A família queria me casar na marra e eu não quis. (E7)
$\mathrm{Na}$ maneira de perceberem e se colocarem no relacionamento sexual, as entrevistadas deixam em evidência que não se definem como sujeitos, mas, sim, como objetos sexuais: Eu perdi a virgindade depois de noiva, mas antes do casamento. Eu nunca senti vontade de fazer sexo. A iniciativa sempre foi do meu marido. (E8)

A construção das diferenças entre os gêneros faz com que as meninas aprendam não apenas a proteger seus corpos, mas também a ocupar um espaço corporal pessoal muito limitado, desenvolvendo assim, ao longo da vida, uma espécie de timidez corporal.

A segregação social e política a que as mulheres foram historicamente conduzidas teve, como conseqüência, sua ampla invisibilidade como sujeitos. Tal invisibilidade foi produzida a partir de múltiplos discursos que caracterizaram a esfera do privado, o mundo doméstico, como o verdadeiro universo da mulher ${ }^{(10)}$. Nesse sentido, as mulheres colocam-se como produto de um processo socializador que destina a elas o papel de esposas, papel que se institui por meio do casamento, e o de mãe, portanto de responsável pelo cuidado dos filhos e, muitas vezes, de toda a família, ainda que, para isso, destruam-se seus sonhos de realização pessoal.

As mudanças corporais por que passa a menina para se tornar mulher foram expressas pelas mulheres estudadas por meio do juízo acerca das relações que existem entre quem experimenta tais mudanças e os outros. Situaram a mama num sistema de normas que estipulam, instituem e convencionam valores e significações. À mama foi instituído um valor estético e nutricional pelas entrevistadas: (...) é uma vaidade que a mulher tem, é uma vaidade. A minha vaidade é a mama. Eu acho que é uma parte do meu corpo que eu tenho que lutar pra não perder ela.(E7) Não vou precisar mais da mama para dar de mamar. (E2)

A vida feminina é ritmicamente marcada por ritos cujo determinante biológico é evidente e intenso. Assim ocorre na menstruação, na maternidade e na menopausa. As mulheres estudadas destacaram, ainda, alguns aspectos que caracterizaram as transformações que chegam com a menstruação, como foi revelado neste depoimento: (...) a partir da menstruação, eu não apanhei mais da minha mãe. (E4)

Junto com as transformações, chegam, também, o medo, o perigo, o desagrado, a mudança na imagem corporal e a percepção do desejo sexual: Depois que veio a menstruação, aí já tem muito perigo! Aí você já fica grávida, já tem perigo... Já é mais diferente, né? Já tem as coisas. (E5) 
$\mathrm{E}$, nesse mecanismo de controle social sobre o corpo, os limites de investidura sobre ele são identificados pelas mulheres, quando reportam que o cuidado com o corpo só se faz quando relacionado à procriação: Fiz exame Papanicolaou no ano passado, porque eu estou grávida e era virgem antes.(E5)

\section{ESTILO DE PARTICIPAÇÃO NA ESCOLHA DO TRATAMENTO}

Por meio dos depoimentos das mulheres estudadas, emergiram temas que possibilitaram apreender as seguintes unidades de significado: 'a mulher é desqualificada para decidir sobre o que diz respeito à sua vida e à sua saúde', evidenciando o desrespeito ao exercício da autonomia; 'a trajetória do tratamento', que mostra como a descoberta do câncer, sua história e causalidade, os procedimentos diagnósticos e o acesso à assistência conduzem-nas à peregrinação em busca de atendimento médico; 'a maneira de enfrentar o diagnóstico', que se relaciona com a expectativa de encontrar respostas sobre a origem da doença e os resultados dos exames, a busca de soluções rápidas e a cristalização de mitos.

Seus relatos evidenciam que, de modo geral, seu caminhar, sua participação no processo de escolha desse tratamento limitou-se ao recebimento de algumas explicações, e a concordar com o que lhe era indicado e segui-lo: O médico explicou sobre a quimioterapia. Foram bons comigo. Me senti a par das decisões. (E2); (...) ela foi marcando e eu fui fazendo, inclusive até, no dia em que eu fiz a biópsia, ela marcou para voltar com oito dias. (E7)

$\mathrm{Na}$ maneira de perceberem e se colocarem na escolha do tratamento clínico e/ou cirúrgico, evidenciouse que as mulheres são desresponsabilizadas, pois, ao obedecerem à autoridade científica do médico, submetemse a procedimentos desconhecidos, definidos por outra pessoa. Destacaram ainda, aspectos que caracterizam a falta de acesso à informação para poderem opinar, aceitar, recusar ou argumentar acerca do tratamento.

Nos casos em que foram esclarecidas pelo médico, preferiram não escolher nenhuma das alternativas propostas, mas adotar aquela que o médico achava mais adequada. Forçá-las a tomar qualquer decisão diferente daquela escolhida pelo médico configuraria constrangimento. Aí ele perguntou pra mim se eu queria operar e eu falei pra ele, o que o senhor acha? Eu falei pra ele: Na opinião do senhor, o que o senhor acha, né?. (E2)

A obediência à autoridade científica do médico, no momento da escolha do procedimento terapêutico, revela que cumprir ordens e agir em restrito respeito ocupa uma posição de destaque nas vidas das entrevistadas. Eu entendi que teria que tirar a mama, mas não tinha claro o porquê; eu nunca tinha tido contato com ninguém assim, que tivesse tirado o seio. (E1)

As regras de conduta e de comportamento, tal como indicam as narrações, são as balizas das normas e convenções socioculturais. Incluem-se aí regras de educação e obediência no relacionamento com o outro gênero.

Pode-se entender que os processos ligados às decisões sobre o corpo feminino são processos culturais, arbitrariamente construídos sem a participação das mulheres e com a finalidade ímpar de assegurar a dominação de uma classe sobre a outra. Neste estudo, o domínio da classe médica, pela força da legitimidade dos saberes em saúde, é evidente sobre a mulher, quando a decisão sobre o tipo de tratamento não é tomada por ela.

As mulheres, ao descreverem a relação médicopaciente, no momento decisório do tratamento, revelam que os médicos as trataram sem diálogo, valendo-se de uma comunicação unilateral. É interessante notar que tal conduta se aproxima daquela relação classificada como dos médicos de escravos do período clássico da cultura grega $^{(11)}$.

Nessa época, as funções médicas eram encaradas como segredos tradicionais e, simultaneamente, como manifestações do poder curador da divindade, com o que o profissional se arrogava a faculdade de decidir sobre a vida e a morte.

As mulheres estudadas, conscientemente ou não, apreenderam seu enquadramento numa classe de seres humanos de menor valor, à qual só é dado o uso de uma medicina oculta, ao vivenciarem, ainda, outro fato: nas raras exceções em que participaram da decisão sobre seu tratamento, não foram elas diretamente, mas, sim, o médico, o marido, o filho ou outro familiar quem teve a palavra final: $O$ médico conversou com o meu marido e o filho. (E3)

Essa negação de autonomia às mulheres classifica-as em outra categoria que não a dos homens livres. Se a idéia básica é que todo ser humano pode decidir sobre si mesmo, esse direito foi negado às mulheres 
entrevistadas neste estudo. Com raras exceções, elas recusaram a subordinação, o conformismo e a desresponsabilização, ao defenderem sua escolha pessoal; quando o fizeram, ficaram sujeitas à denominação "pacientes difíceis" ${ }^{(12)}$. Aí eu disse: não! Eu não aceito, doutor, tirar. Deus me deu dois peitos, vai me levar com os dois, não tiro, não aceito e não me faça surpresa pra mim tirar, pois eu não aceito fazer nada no meu peito, não me tirem o peito. (E6)

A tradição e as relações de poder atribuem aos médicos funções específicas de saber legitimado e poder sobre o corpo ${ }^{(13)}$. Poder-se-ia dizer que o exercício do poder, aquele que se dá entre sujeitos capazes de resistir, é constituído por "manobras", "técnicas", "disposições". Essas ações são, por sua vez, resistidas e contestadas, respondidas, absorvidas, aceitas ou transformadas, para não se transformarem em relações de violência ${ }^{(10)}$.

Ao considerar os vários indicadores que devem ser observados pelo médico, na escolha do tratamento, e que os procedimentos terapêuticos para o câncer de mama são múltiplos e estão em constante evolução e inovação, a falta de informação ou a informação insuficiente evidenciou, para as mulheres deste estudo, que o campo do domínio científico é uma prerrogativa exclusiva do médico, como se este detivesse uma habilidade mágica para o câncer.

No entanto, a informação é a base para as decisões autônomas do paciente. Ser informado é, então, um direito do paciente ${ }^{(9)}$.

Os médicos sentem seu profissionalismo ameaçado quando as pacientes exigem respeito a sua autonomia $^{(14)}$. O princípio da autonomia, embora adulterado por uma concepção paternalista, é parte da deontologia hipocrática. As normas hipocráticas expressam que a razão e o saber do profissional é que devem orientar sua conduta, e não o respeito à autonomia da pessoa assistida $^{(11,13)}$.

Ao narrarem o vivido, elas reconheceram que deixaram de solicitar informações, por esquecimento, inibição ou vergonha, na presença da autoridade: Eu não perguntei muita coisa pra ela. Na hora, a gente não lembra de perguntar nada. (E6); Não tenho conversado e tirado dúvidas, não sei se vamos conversar. (E3). Deixam em evidência, também, que desconhecem sua capacidade de enfrentarem as adversidades, assim como de expressarem sentimentos, pedirem ajuda quando necessário e aprenderem compartilhar suas necessidades.

Os médicos julgam as mulheres como incapazes de tomarem decisões, pois não acreditam que elas tenham capacidade de compreender o que lhes é comunicado no momento da revelação dos resultados dos exames, por estarem emocionalmente abaladas e não reterem as informações. Preferem, então, não explicar nada e garantir sua superioridade ${ }^{(3-4)}$.

A forma de se ver numa relação, marcada pela supervalorização de um e impotência do outro, pode desencadear insatisfação e danos à vida dessas mulheres, isso porque a comunicação médico-paciente torna-se parcial, não permitindo a interação e a participação do cliente na escolha do tratamento.

Foi apreendido pelas mulheres que os médicos não aceitam interrogatórios nem pedidos de esclarecimentos ou de informações extras sobre sua decisão. Isso significa que, nesse domínio, não existem negociações. Uma vez que o médico se pronuncie, deixa de existir o ponto de vista próprio do doente. Os depoimentos evidenciam que ocorreu demarcação da autoridade e da responsabilidade que o saber técnico assegura: Eu só soube do tratamento com a médica da radioterapia. Ela e vocês dão muita dica pra gente, bastante benefício, né? (E5)

As entrevistadas reconheceram haver diferenças no processo comunicativo que se estabelece entre os profissionais de saúde e elas, diferenças que tanto mais se acentuam quanto mais especializada é a prática, pois maior distância passa a haver entre os saberes. Esse distanciamento faz silenciar aquele que dispõe de menor competência comunicativa e reforça o status daqueles que detêm maiores conhecimentos. Eu não conversei, não participei do que eles falaram que era pra eu fazer. A radioterapia foi falada pelo outro médico. (E5)

O ser humano é capaz de ajustar-se à realidade, transformando-a e fazendo escolhas. Na medida em que o ser humano perde a capacidade de fazer escolhas, vai se submetendo às decisões que não são mais suas, tomando essa submissão como uma realidade e ajustando-se a ela, minimizando-se, deixando de integrarse e acomodando-se ${ }^{(15)}$.

Esse movimento de apassivamento revelou-se com freqüência entre as mulheres estudadas, que se constituíram como sujeitos que obedecem e reconhecem sua inferioridade: Na presença do médico especialista, eu não perguntei nada pra ele. Aceitei todas as decisões sobre o tratamento. Ele decidiu, né? (E4)

A falta de informação ou informação insuficiente garante a superioridade do médico. Assim, a hegemonia 
do saber médico prevalece, não permitindo a participação da mulher ${ }^{(4)}$.

Ao narrarem o sentimento de desqualificação para decidir sobre o tratamento, as mulheres deixam transparecer que elas buscam, nos outros profissionais da equipe de saúde, a informação de que precisam para se adaptar. (...) a médica não falou nada! Quem falou comigo sobre o tratamento foi a psicóloga.. Isso mexeu comigo do pé à cabeça. Mexeu completamente comigo. Eu não sou mais quem eu era. (E7)

Algumas mulheres anunciaram que, ao se arriscarem em mostrarem-se conhecedoras de seus corpos, foram colocadas "em xeque" suas competências, pelos profissionais de saúde, como revelado a seguir: $A$ médica me inspecionou tudo e falou assim "ah, isso aí não é nada, isto aí é uma glândula mamária, não é nada". (E3)

Ao narrarem suas vivências, as entrevistadas deixaram transparecer que repudiaram a realização dos procedimentos diagnósticos que ajudaram definir o tipo de tratamento e apresentaram sentimentos negativos de diversa ordem, relacionados ao impacto do diagnóstico e tratamentos.

Considerando o impacto dos procedimentos médicos no corpo, as mulheres estudadas perceberam que não tiveram a oportunidade de discutir o tratamento com os médicos, mas colocaram-se como objeto ao revelarem sua tensão, preocupação e desconhecimento quanto aos procedimentos realizados: Eles fizeram uma biópsia para ver o que era, e, se fosse preciso, iam tirar tudo já na hora. Só que foi feita a biópsia, e eu não saí operada da sala. Ninguém me disse por quê, e estou de alta, para voltar daqui uma semana. (E3)

A análise dos depoimentos das participantes apontou, ainda, que o acesso à assistência foi pontuado por dificuldades, as quais as obrigaram a buscar um atendimento que não tem como alvo proporcionar um auxílio eficaz à pessoa. Vale lembrar que isso ocorre porque o sistema de assistência à saúde prega a beneficência como princípio: não causar mal ao paciente e manter a vida, mesmo com qualidade inferior ${ }^{(8)}$.

A peregrinação expressa pelas mulheres, para terem acesso à assistência, revela que a beneficência é a regra norteadora da prática médica, tem o médico como protetor e, de certa forma, o dono do paciente, responsável único pelo bem do paciente, seu bem-estar e seus interesses, nas várias formas do agir profissional.

O significado de experienciar uma situação de ser doente significou, para muitas delas, vivenciar a injustiça social quando se conformaram com uma assistência insatisfatória, a única disponível, porém, para uma condição socioeconômica desprivilegiada. Significou, portanto, para elas, que o direito à saúde relaciona-se à classe social a que se pertence.

Além das dificuldades de acesso, de distribuição e de serviço e saberes, outras barreiras de acesso são descritas pelas mulheres que são de igual importância como a falta de recursos materiais em seus locais de origem e a distância geográfica: Eu fui ao médico de lá, e ele me encaminhou, porque lá não tinha recurso, já estava grande $e$ saía sangue, sangue, sangue. (E2). O marido arrumou dinheiro e me mandou pra São Paulo, sozinha. (E1)

Da mesma forma, as mulheres anunciam que 0 processo de investigação diagnóstica significou que o percurso para se ter acesso ao atendimento faz-se de forma fragmentada e desarticulada.

Foi apreendido pelas entrevistadas que a liberdade de decisão, premissa do princípio de autonomia e responsabilidade, foi substituída pelas idéias de destino e culpa, como expresso neste depoimento: $O$ especialista que me atendeu, assim que me examinou, disse "ah, se você tivesse vindo há mais tempo, não precisaria tirar toda a mama, retiraria só um terço ... tem que fazer o mais rápido possível essa cirurgia porque senão vai subir para o pescoço".(E1)

Nas relações historicamente desiguais e assimétricas, como é a relação entre os profissionais de saúde, os serviços de saúde e os usuários (a mulher, em particular), há um terreno fértil para a violência simbólica, traduzida por submissão à vontade e à ação do outro ${ }^{(16)}$. Enquanto instrumentos estruturados e estruturantes de comunicação e de conhecimento, os "sistemas simbólicos" - arte, religião, língua - cumprem a função de instrumento de imposição ou que legitima a dominação, os quais contribuem para assegurar a dominação de uma classe sobre outra (violência simbólica), dando o reforço às relações de força que as fundamentam. A violência simbólica, por trazer em sua origem a incorporação dos processos de minimização da dor, do sofrimento e da perda do outro, cria as condições ideais para que a violência pareça natural aos olhos de quem a sofre.

\section{CONSIDERAÇÕES FINAIS}

Ao relatarem sua participação no processo de tomada de decisão sobre o tratamento do câncer de mama, 
as mulheres estudadas permitiram-nos apreender o que significou para elas lidar com limites. Falar sobre essa participação significou, portanto, falar de ética. Ficou claro, em seu processo interpretativo, que a configuração valorativa estabelecida por elas, a respeito da participação, foi permeada por transgressões de valores e princípios, as quais as distanciaram da possibilidade de se sentirem como seres humanos autônomos, capazes e responsáveis por si mesmas.

Percebem elas, assim, que não participaram desse processo decisório em razão de serem rotuladas como desqualificadas para decidirem sobre seus corpos e suas vidas. Isso significou para elas que a autonomia está longe de ser alcançada numa sociedade em que o atendimento à saúde estrutura-se por meio das relações sociais hierarquizadas, nas quais as relações de poder se dão entre classes, gêneros e saberes.

Os resultados deste estudo permitiram-nos apreender que, em termos da relação sujeito-objeto, no processo de tomada de decisão sobre o tratamento do câncer de mama, a mulher é colocada como objeto de contemplação e como sujeito de obediência à decisão médica. Permitiram, ainda, apreender que emerge uma grande diferença na direção da relação sujeito-objeto, quando se atribuem prioridades diferentes a cada um dos princípios de autonomia, justiça, beneficência, nãomaleficência e oportunidades iguais no atendimento à saúde. Apreende-se que as mulheres do estudo colocaram-se como objetos do cuidado médico, em decorrência de um discurso científico que se atribui à tarefa de buscar o bem e o melhor para elas.

As mulheres, ao revelarem que a autonomia, tão almejada e bandeira de luta do movimento feminista, está

\section{REFERÊNCIAS BIBLIOGRÁFICAS}

1. Neufeld KR, Degner LF, Dick JAM. A nursing intervention strategy to foster patient involvement in treatment decisions. Oncol Nurs Forum 1993; 20(4):631-5.

2. Beaver L, Luker KA, Owens RG, Leinster SJ, Degner LF, Sloan JA. Treatment decision making in women newly diagnosed with breast cancer.Cancer Nurs 1996; 19(1):8-19. 3. Degner LF, Kristjanson LJ, Bowman D, Sloan JA, Carriere $\mathrm{KC}$, O'neil $\mathrm{J}$, et al. Information needs and decisional preferences in women with breast cancer. JAMA 1997; 277(18):1485-92.

4. Fallowfield L. Offering choice of surgical treatment to women with breast cancer. Patient Educ Counseling 1997; 30 (3): 209-14.

5. Mamede MV. Reabilitação de mastectomizadas: um novo enfoque assistencial. [Tese]. Ribeirão Preto (SP): Escola de Enfermagem Ribeirão Preto/USP; 1991 longe de ser alcançada, deixam transparecer que é por meio da relação do ser humano com o mundo que se transforma e se capta a presença das coisas, como também é por meio dessa relação que se constitui o domínio da mera opinião sobre coisas, fatos e eventos. No discurso das mulheres estudadas, reencontramos a tão falada questão da autonomia do sujeito e do consentimento à submissão a um ato ou a um conjunto de atos prescritos para o tratamento da doença.

As mulheres situaram o saber médico dentro de um espaço histórico-cultural de dominação, o qual penetra seus espaços histórico-culturais, sobrepondo a elas o seu sistema de valores. Anunciaram a existência de relações estruturais rígidas e verticais na relação médico-paciente, não havendo lugar para o diálogo. $\mathrm{Na}$ verdade, ao descreverem expressões de invasão cultural, as mulheres revelam os descaminhos de libertação e os caminhos de domestificação.

Analisando os dados que compõem a construção da identidade de gênero desse grupo de mulheres, revelam semelhantes relações que, historicamente, constituíram a consciência de gênero feminino como consciência oprimida. Essas mulheres denunciaram a inexistência de experiência dialógica em seu processo de socialização, o que, talvez, possa explicar as razões da insegurança sobre si mesmas, sem contar com o direito de dizer sua palavra, mas apenas com o dever de escutar e obedecer.

Um caminho possível que pode ser traçado pela enfermagem, para auxiliar no resgate da autonomia das mulheres, sobretudo aquele que diz respeito a seus corpos e suas vidas, acreditamos que seja o da reflexão bioética, aberta, vivida com experiências dialógicas entre a mulher e os profissionais de saúde.

6. Blumer H. Symbolic interactionism. Perspective and method. Englwood Cliffs - New Jersey: Prentice - Hall; 1969. 7. Minayo MCdeS. O desafio do conhecimento. Pesquisa qualitativa em saúde. $5^{\underline{a}}$ ed. São Paulo: Hucitec- Abrasco; 1998.

8. Kipper DJ, Clotet J. Princípios da beneficência e nãomaleficência. In: Costa SIF, Oselka G, Garrafa V. Iniciação à bioética. Brasília: Conselho Federal de Medicina; 1998. p. 37-52.

9. Muñoz DR, Fortes PAC. O princípio da autonomia e o consentimento livre e esclarecido. In: Costa SIF, Oselka G, Garrafa V. Iniciação à bioética. Brasília: Conselho Federal de Medicina; 1998. p.53-70.

10. Louro GL. Gênero, sexualidade e educação: uma perspectiva pós-estruturalista. $2^{\mathrm{a}}$ ed. Petrópolis: Vozes; 1997. 11. Fortes PAdeC Ética e saúde: questões éticas, deontológicas e legais, tomada de decisões, autonomia e direitos do paciente, estudo de casos. São Paulo: EPU; 1998. 
12. Fiorino V. Ser cidadã francesa: uma reflexão sobre os princípios de 1789. In: Bonacchi G, Groppi A, organizadoras. $\mathrm{O}$ dilema da cidadania: direitos e deveres das mulheres. São Paulo: Editora da Universidade Estadual Paulista; 1995. p.79-108.

13. Berlinguer G. Ética da saúde. São Paulo: Hucitec; 1996. 14. Carapinheiro G. Saberes e poderes no hospital. Uma sociologia dos serviços hospitalares. Lisboa: Ed. Afrontamento; 1993.

15. Freire P. Extensão ou comunicação? 5 ed. Rio de Janeiro: Paz e Terra; 1980.

16. Bourdieu P. Sobre o poder simbólico. In: Bourdieu P. O poder simbólico. $2^{\underline{a}}$ ed. Rio de Janeiro: Bertrand Brasil; 1998. p.7-16. 